\title{
Alemtuzumab CARE-MS I 5-year follow-up
}

Durable efficacy in the absence of continuous MS therapy OPEN

Eva Havrdova, MD, PhD

Douglas L. Arnold, MD Jeffrey A. Cohen, MD

Hans-Peter Hartung, $\mathrm{MD}, \mathrm{PhD}$

Edward J. Fox, MD, PhD Gavin Giovannoni, MD, $\mathrm{PhD}$

Sven Schippling, MD

Krzysztof W. Selmaj, $\mathrm{MD}, \mathrm{PhD}$

Anthony Traboulsee, MD

D. Alastair S. Compston, $\mathrm{PhD}$, FRS

David H. Margolin, MD, $\mathrm{PhD}$

Karthinathan Thangavelu, $\mathrm{PhD}$

Claudio E. Rodriguez, MD

Darlene Jody, MD

Richard J. Hogan, PhD

Panos Xenopoulos, $\mathrm{PhD}$

Michael A. Panzara, MD, $\mathrm{MPH}$

Alasdair J. Coles, MD, $\mathrm{PhD}$

On behalf of CARE-MS I and CAMMS03409 Investigators

Correspondence to

Dr. Havrdova:

eva.havrdova@lf1.cuni.cz

\section{Editorial, page 1098}

\section{See page 1117}

Supplemental data at Neurology.org

\section{ABSTRACT}

Objective: To evaluate 5-year efficacy and safety of alemtuzumab in treatment-naive patients with active relapsing-remitting MS (RRMS) (CARE-MS I; NCT00530348).

Methods: Alemtuzumab-treated patients received treatment courses at baseline and 12 months later; after the core study, they could enter an extension (NCT00930553) with as-needed alemtuzumab retreatment for relapse or MRI activity. Assessments included annualized relapse rate (ARR), 6-month confirmed disability worsening (CDW; $\geq 1$-point Expanded Disability Status Scale [EDSS] score increase [ $\geq 1.5$ if baseline EDSS $=0$ ]), 6-month confirmed disability improvement (CDI; $\geq 1$-point EDSS decrease [baseline score $\geq 2.0]$ ), no evidence of disease activity (NEDA), brain volume loss (BVL), and adverse events (AEs).

Results: Most alemtuzumab-treated patients (95.1\%) completing CARE-MS I enrolled in the extension; $68.5 \%$ received no additional alemtuzumab treatment. ARR remained low in years 3, 4, and $5(0.19$, 0.14 , and 0.15$)$. Over years $0-5,79.7 \%$ were free of 6 -month CDW; 33.4\% achieved 6-month CDI. Most patients $(61.7 \%, 60.2 \%$, and $62.4 \%)$ had NEDA in years 3, 4, and 5 . Median yearly BVL improved over years 2-4, remaining low in year 5 (years 1-5: $-0.59 \%,-0.25 \%,-0.19 \%$, $-0.15 \%$, and $-0.20 \%)$. Exposure-adjusted incidence rates of most AEs declined in the extension relative to the core study. Thyroid disorder incidences peaked at year 3 and subsequently declined.

Conclusions: Based on these data, alemtuzumab provides durable efficacy through 5 years in the absence of continuous treatment, with most patients not receiving additional courses.

ClinicalTrials.gov identifier: NCT00530348; NCT00930553.

Classification of evidence: This study provides Class III evidence that alemtuzumab durably improves efficacy outcomes and slows BVL in patients with RRMS. Neurology ${ }^{\circledR}$ 2017;89:1107-1116

\section{GLOSSARY}

$\mathbf{A E}=$ adverse event; $\mathbf{A R R}=$ annualized relapse rate; $\mathbf{B P F}=$ brain parenchymal fraction; $\mathbf{B V L}=$ brain volume loss; $\mathbf{C D I}=$ confirmed disability improvement; $\mathbf{C D W}$ = confirmed disability worsening; DMT = disease-modifying therapy; EAIR = exposure-adjusted incidence rate; EDSS = Expanded Disability Status Scale; IAR = infusion-associated reaction; ITP = immune thrombocytopenia; NEDA = no evidence of disease activity; RRMS = relapsing-remitting MS; SC IFN- $\boldsymbol{\beta}-\mathbf{1} \mathbf{a}$ = subcutaneous interferon $\boldsymbol{\beta}-\mathbf{1}$ a.

Alemtuzumab (LEMTRADA; Sanofi Genzyme, Cambridge, MA) is a humanized monoclonal antibody that selectively targets CD52, an antigen highly expressed on T and B lymphocytes. ${ }^{1}$ Binding of alemtuzumab to CD52 results in depletion of circulating $\mathrm{T}$ and $\mathrm{B}$ cells, ${ }^{2,3}$ following which a distinct pattern of $\mathrm{T}$ - and $\mathrm{B}$-cell repopulation and a shift in cytokines toward a less

From the Department of Neurology and Center for Clinical Neuroscience (E.H.), First Faculty of Medicine, Charles University and General University Hospital in Prague, Czech Republic; NeuroRx Research (D.L.A.), Montréal; Department of Neurology and Neurosurgery (D.L.A.), Montréal Neurological Institute, McGill University, Québec, Canada; Mellen Center (J.A.C.), Cleveland Clinic, OH; Department of Neurology and Center for Neuropsychiatry (H.-P.H.), Medical Faculty, Heinrich-Heine University, Düsseldorf, Germany; MS Clinic of Central Texas (E.J.F.), Central Texas Neurology Consultants, Round Rock; Queen Mary University of London (G.G.), Barts and The London School of Medicine, UK; Neuroimmunology and Multiple Sclerosis Research (S.S.), Department of Neurology, University Hospital Zürich and University of Zürich, Switzerland; Department of Neurology (K.W.S.), Medical University of Łódź, Poland; The University of British Columbia (A.T.), Vancouver, Canada; Department of Clinical Neurosciences (D.A.S.C., A.J.C.), University of Cambridge, UK; Sanofi (D.H.M., K.T., C.E.R., D.J., M.A.P.), Cambridge, MA; Evidence Scientific Solutions (R.J.H.), Sydney, NSW, Australia; and Evidence Scientific Solutions (P.X.), Philadelphia, PA. M.A.P. is currently affiliated with Wave Life Sciences, Cambridge, MA.

Coinvestigators are listed at Neurology.org.

Go to Neurology.org for full disclosures. Funding information and disclosures deemed relevant by the authors, if any, are provided at the end of the article. The Article Processing Charge was funded by Sanofi.

This is an open access article distributed under the terms of the Creative Commons Attribution-NonCommercial-NoDerivatives License 4.0 (CC BY-NC-ND), which permits downloading and sharing the work provided it is properly cited. The work cannot be changed in any way or used commercially without permission from the journal. 
inflammatory pattern occur. Both mechanisms may be relevant to the durable efficacy of this drug. ${ }^{4}$

Compared with the active treatment subcutaneous interferon $\beta$-1a (SC IFN- $\beta$ - 1 a; Rebif; EMD Serono Inc., Rockland, MA), alemtuzumab significantly reduced the annualized relapse rate (ARR) in patients with active relapsing-remitting MS (RRMS) who either were treatment-naive (phase 2 CAMMS223 study [NCT00050778] ${ }^{5}$ and phase 3 Comparison of Alemtuzumab and Rebif Efficacy in Multiple Sclerosis [CARE-MS] I study $[\text { NCT00530348] })^{6}$ or had an inadequate response ( $\geq 1$ relapse) to prior therapy (phase 3 CARE-MS II study [NCT00548405]). ${ }^{7}$ In CAMMS223 and CARE-MS II, alemtuzumab also increased proportions of patients who were free of 6-month confirmed disability worsening (CDW)., ${ }^{5,7}$ Alemtuzumab increased proportions with no evidence of disease activity (NEDA) in the 2-year phase 3 CARE-MS studies $^{6,7}$ and reduced brain volume loss (BVL) in all 3 clinical trials, compared with SC IFN- $\beta-1 \mathrm{a} .{ }^{5-7}$ The most common adverse events (AEs) with alemtuzumab were infusion-associated reactions (IARs); autoimmune AEs were also associated with treatment. $^{5-7}$ Based on the positive benefit-risk profile demonstrated in these trials, alemtuzumab is currently licensed in over 60 countries worldwide for treatment of adults with $\mathrm{RRMS}^{8,9}$ and is the only approved treatment that does not require continuous dosing to provide durable efficacy in patients with this disease.

We report interim results through 3 years of an extension study (NCT00930553) in patients who received alemtuzumab during the core CARE-MS I trial, constituting a total of 5 years of follow-up from CARE-MS I enrollment.

METHODS Patients and procedures for CARE-MS I core study. The study design for the 2-year CARE-MS I core study has been published previously. ${ }^{6}$ Briefly, CARE-MS I was a randomized, rater-blinded, active-controlled, head-to-head trial of alemtuzumab compared with SC IFN- $\beta-1 \mathrm{a}$ in patients who were treatment-naive and had active RRMS ( $\geq 2$ relapses in the previous 2 years and $\geq 1$ relapse in the prior year).

Procedures for the extension study. This analysis reports findings from alemtuzumab-treated patients who completed CARE-MS I and continued into the extension, in which they could receive additional alemtuzumab courses (each $12 \mathrm{mg} / \mathrm{d}$ IV on 3 consecutive days) upon evidence of MS disease activity (and $\geq 48$ weeks since the prior course). Eligibility criteria for retreatment were $\geq 1$ protocol-defined relapse or $\geq 2$ new/enlarging T2 hyperintense and/or gadolinium (Gd)-enhancing brain or spinal cord lesions on MRI. Retreatment-disqualifying criteria included, but were not limited to, pregnancy, diagnosis of immune thrombocytopenia (ITP) or other immune cytopenia, and history of malignancy (except basal cell carcinoma) or antiglomerular basement membrane disease. The decision on whether to initiate retreatment in eligible patients was left to the treating physician and patient, as was the decision to provide another licensed disease-modifying therapy (DMT).

Efficacy assessments and endpoints. Relapse events required objective signs on examination, lasting $\geq 48$ hours, and were confirmed by the investigator. The Expanded Disability Status Scale (EDSS) was assessed quarterly and for evaluation of suspected relapses by raters blinded to previous treatment assignment and treatment history throughout the extension. Annual MRI scans were assessed by blinded imaging specialists at NeuroRx Research (Montréal, Canada; for lesion-based analyses) and the Cleveland Clinic MS MRI Analysis Center (Cleveland, OH; for brain parenchymal fraction $[\mathrm{BPF}]$ analysis).

Clinical efficacy endpoints evaluated over years $0-5$ included the following: ARR; proportion of relapse-free patients; 6-month CDW ( $\geq 1.0$-point EDSS score increase from core study baseline $[\geq 1.5$ if baseline EDSS score $=0$ ]; formerly termed sustained accumulation of disability ${ }^{10}$ ); mean change from baseline EDSS score; proportions of patients with EDSS scores that were improved ( $\geq 1.0$-point decrease), worsened ( $\geq 1.0$-point increase), or stable ( $\leq 0.5$-point change) compared with baseline; and 3-, 6-, or 12-month confirmed disability improvement (CDI; $\geq 1$.0-point decrease from core study baseline EDSS score, in patients with baseline EDSS scores $\geq 2.0$ ).

MRI lesion outcomes examined over years $0-5$ included proportions of patients with Gd-enhancing, new/enlarging T2 hyperintense, and new nonenhancing T1 hypointense lesions. Median percentage BVL from baseline and per year was calculated.

NEDA was evaluated annually and cumulatively (sustained NEDA over years 3-5). NEDA was defined as no evidence of clinical disease activity (absence of both relapses and 6-month $\mathrm{CDW}$ ) and no evidence of MRI lesion activity (absence of both new Gd-enhancing and new/enlarging T2 hyperintense lesions).

Safety monitoring. Safety was evaluated by review of AEs, serious AEs, medical events of interest, and laboratory tests (including thyroid function [at least quarterly], hematology [at least monthly], serum creatinine [monthly], and urinalysis with microscopy [monthly]). All safety monitoring procedures continued for 4 years after last alemtuzumab administration, or until study end, whichever occurred later. IARs were defined as any $\mathrm{AE}$ with onset during infusion or $\leq 24$ hours after the end of infusion.

Classification of evidence. This analysis evaluates the longterm efficacy and safety of alemtuzumab and provides Class III evidence that alemtuzumab improves ARR, MRI lesion outcomes, and BVL over 5 years in treatment-naive patients with active RRMS and that high proportions of patients achieve NEDA. These effects were observed in the absence of continuous treatment and with most (68.5\%) patients receiving no alemtuzumab retreatment through 5 years.

Statistical analysis. Analyses were based on available data (without imputation) on all alemtuzumab $12 \mathrm{mg}$ patients with 


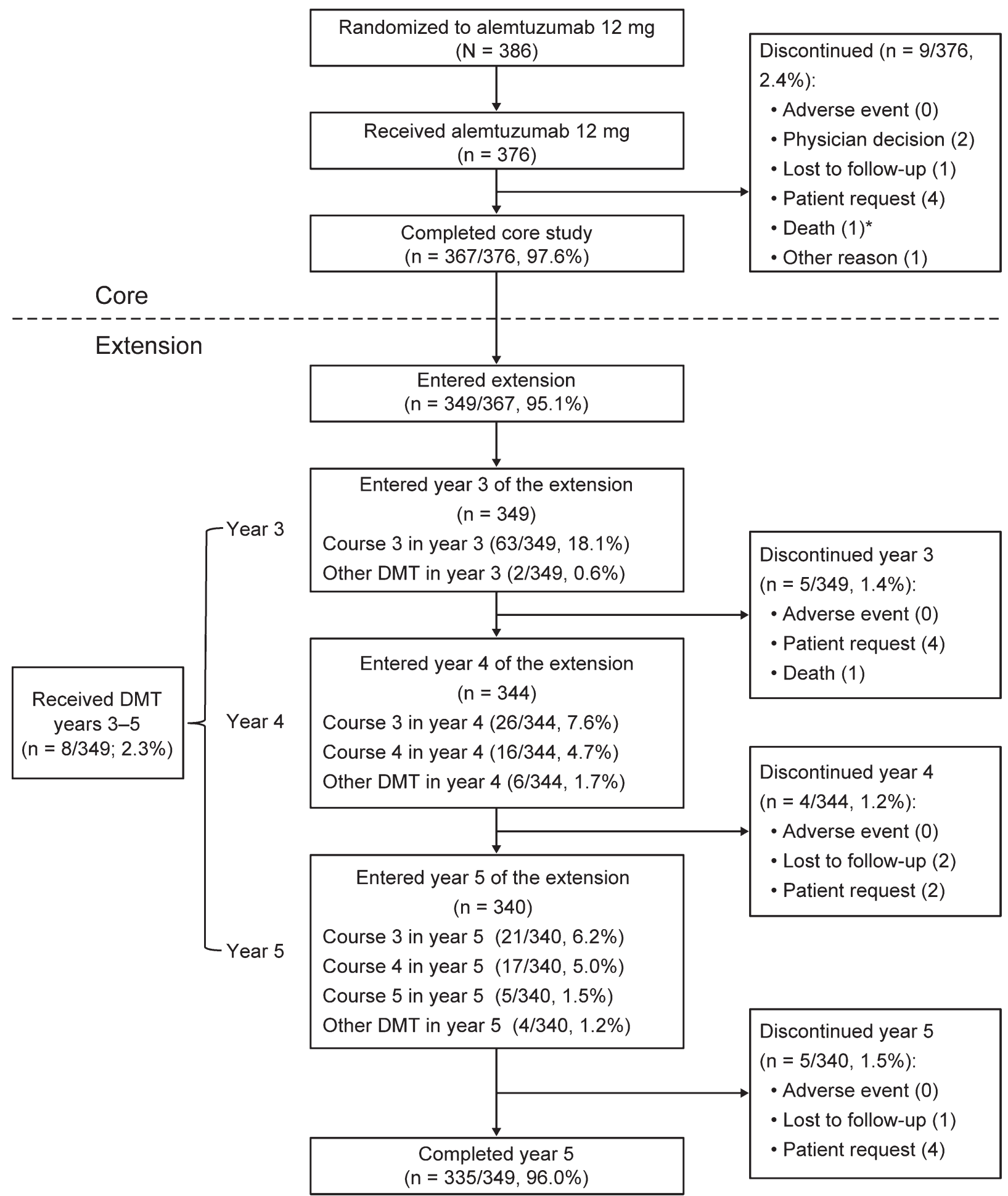

Disposition schematic includes patient participation from the core CARE-MS I study through the long-term extension study. DMTs include fingolimod ( $\mathrm{n}=1$ ), glatiramer acetate $(n=2)$, interferon $\beta-1 a(n=2)$, interferon $\beta-1 b(n=3)$, and natalizumab $(n=1)$. *The death that occurred in the core study was deemed not related to treatment. CARE-MS = Comparison of Alemtuzumab and Rebif Efficacy in Multiple Sclerosis; DMT = disease-modifying therapy.

up to 5 years of follow-up from first dose in CARE-MS I, with an interim cutoff date of October 4, 2014, in the extension.

ARR was estimated using negative binomial regression with robust variance estimation and covariate adjustment for the geographic region. Proportions of patients with 6-month CDW or 3-, 6-, or 12-month CDI were estimated with the Kaplan-Meier method. Percentage of patients with improvement, stability, or worsening from the baseline EDSS score was reported.

Safety data were reported as incidences (percentage of patients with $\geq 1$ event) and exposure-adjusted incidence rates (EAIRs) per 100 patient-years ([number of patients with specific event divided by total annual exposure-time among patients at risk of 
A

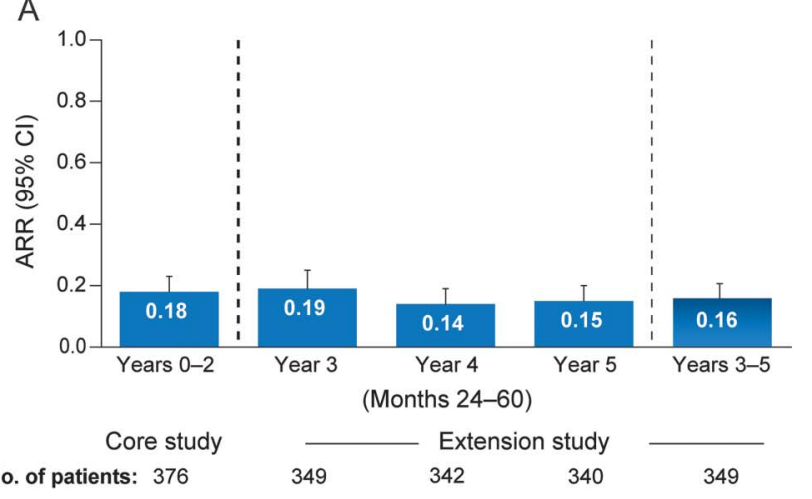

B

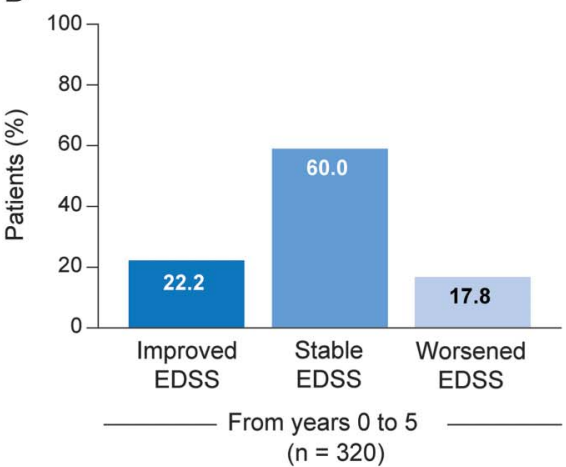

$\mathrm{C}$

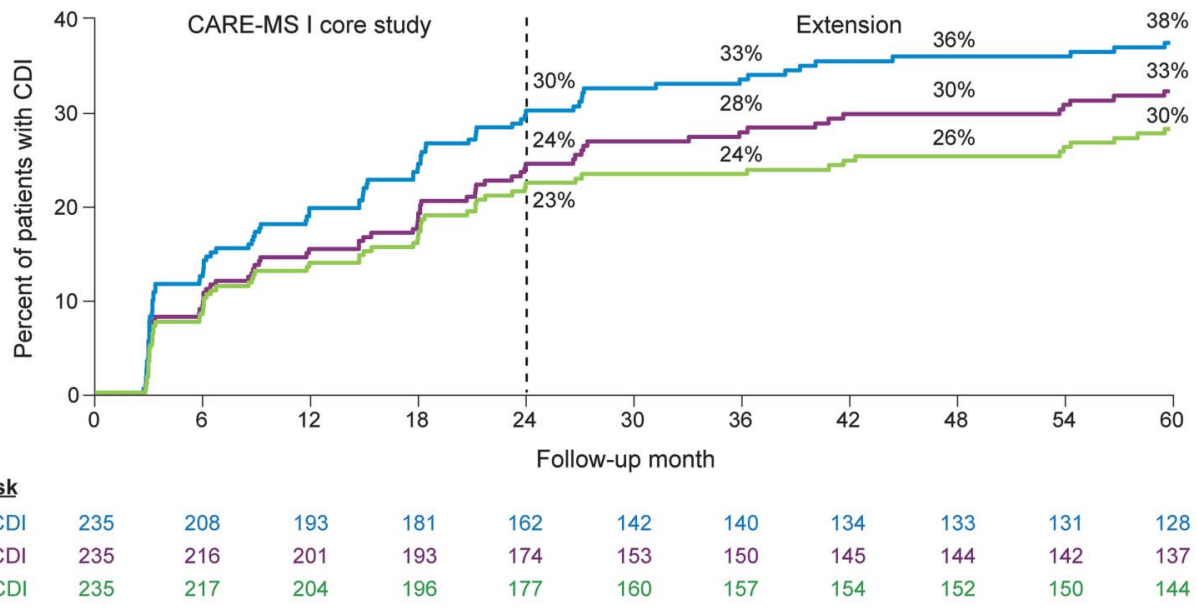

D

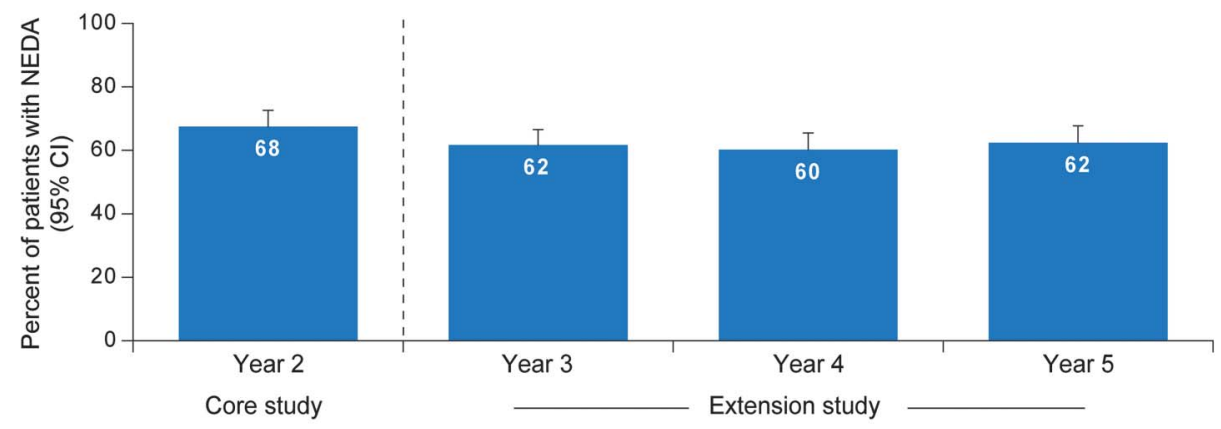

No. of patients:

326

319

\begin{tabular}{|lllll|}
\hline Free of relapse (\%) & 89 & 84 & 87 & 88 \\
Free of 6-month CDW (\%) & 94 & 95 & 94 & 94 \\
Free of clinical disease & 85 & 82 & 84 & 85 \\
activity (\%) & & & 87 & 70 \\
\hline Gd-enhancing T, lesion-free* (\%) & 93 & 90 & 71 & 70 \\
New/enlarging T, lesion-free (\%) & 78 & 72 & 70 & 70 \\
Free of MRI lesion activity (\%) & 77 & 72 & & 70 \\
\hline
\end{tabular}

(A) ARR over 5 years in alemtuzumab patients. Results are shown for all patients who received alemtuzumab 12 mg in the core CARE-MS I study and then enrolled in the extension. A post hoc analysis revealed no statistically significant difference between ARRs in individual extension years (years 3, 4, and 5) and the ARR in years 0-2. (B) EDSS score change in alemtuzumab patients over 5 years. Proportion of patients with improved ( $\geq 1.0$-point decrease), stable ( $\leq 0.5$-point change), or worsened ( $\geq 1$.0-point increase) EDSS scores at year 5 compared with core study baseline. EDSS score changes are shown for all patients who received alemtuzumab $12 \mathrm{mg}$ in the core study and enrolled in the extension. (C) Proportion of alemtuzumab patients with 3-, 6-, or 12-month CDI over 5 years. Kaplan-Meier analysis of time to 3-, 6-, or 12-month CDI is shown for all patients who received alemtuzumab $12 \mathrm{mg}$ in the core CARE-MS I study and then enrolled in the extension. (D) Proportion of alemtuzumab patients with NEDA over 5 years. Results are shown for all patients who received alemtuzumab $12 \mathrm{mg}$ in the core CARE-MS I study and then enrolled in the extension. *Baseline percentage of patients Gd-enhancing lesion-free: $54 \%$. ARR = annualized relapse rate; CARE-MS = Comparison of Alemtuzumab and Rebif Efficacy in Multiple Sclerosis; CDI = confirmed disability improvement; $\mathrm{CDW}=$ confirmed disability worsening; EDSS = Expanded Disability Status Scale; Gd = gadolinium; NEDA = no evidence of disease activity . 
Figure 3 Brain volume loss over 5 years in alemtuzumab patients
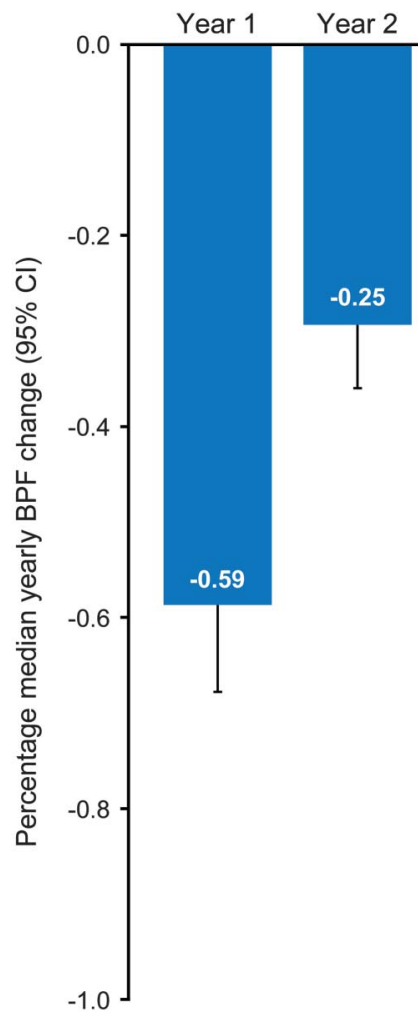

No. of patients: 367

351

320

314

312

Median yearly percentage change in BPF is shown for all patients who received alemtuzumab $12 \mathrm{mg}$ in the core CARE-MS I study and then enrolled in the extension. BPF = brain parenchymal fraction; CARE-MS = Comparison of Alemtuzumab and Rebif Efficacy in Multiple Sclerosis.
$3-5$. The most common reason given by investigators for alemtuzumab retreatment was relapse $(51.0 \%$ of retreatment courses for which a reason was provided), followed by MRI lesion activity (25.9\%), and combined relapse and MRI lesion activity (23.1\%).

Efficacy. ARR remained low during the extension, similar to that in the core study (figure 2A). ${ }^{6}$ Mean EDSS score changes from core study baseline were improvements (i.e., reductions) at year $2(-0.16)$, at year $3(-0.10)$, at year $4(-0.09)$, and 0.00 at year 5 . Compared with core study baseline, $60.0 \%$ of patients at year 5 showed stable EDSS scores; $22.2 \%$ showed improved scores ( $\geq 1$-point decrease) and $17.8 \%$ showed worsened scores ( $\geq 1$-point increase; figure 2B). Over 5 years, $79.7 \%$ (95\% CI 75.1\%$83.6 \%$ ) of patients were free of 6-month CDW, and $33.4 \%$ (95\% CI 27.5\%-40.1\%) achieved 6-month CDI (figure 2C).

Most alemtuzumab-treated patients were free of clinical disease activity or MRI lesion activity during each extension year and most also attained NEDA (figure 2D). Cumulatively over years 3-5, most patients showed no clinical (65.3\%) or MRI lesion (53.8\%) activity, and $39.5 \%$ attained sustained NEDA. During each extension year, most patients were free of new T1 hypointense lesions (year 3, 89.2\%; year 4, $85.4 \%$; year $5,85.4 \%$ ).

The rate of yearly BVL continued to decrease after the core study and seemed to stabilize in years 3, 4, and 5 (figure 3). Median cumulative BPF change from baseline to year 5 was $-1.352 \%$.

Further analyses evaluated outcomes among the

initial occurrence of the event] $\times 100$ ) in the reported time cohorts. ${ }^{11}$ Autoimmune AEs were reported using time of first AE occurrence over total follow-up time ( $0-5$ years).

Standard protocol approvals, registrations, and patient consents. This trial is registered with ClinicalTrials.gov (NCT00530348; NCT00930553). All procedures were approved by local institutional ethics review boards of participating sites. Patients provided written informed consent.

RESULTS Patients. Of the 367 alemtuzumab patients completing CARE-MS I, 349 (95.1\%) entered the extension study; of these, 335 (96.0\%) remained on study through Month 60 (year 5; figure 1).

In the core study, alemtuzumab patients received $12 \mathrm{mg}$ on 5 consecutive days at baseline and 3 consecutive days 12 months later. In the extension study, $239(68.5 \%)$ alemtuzumab patients received no alemtuzumab retreatment; 341 (97.7\%) received no other DMT; and $235(67.3 \%)$ received neither alemtuzumab retreatment nor other DMT. Of the $110 \mathrm{pa}-$ tients who received alemtuzumab retreatment (table e-1 at Neurology.org), 77 (70.0\%), 28 (25.5\%), and $5(4.5 \%)$ received a total of 1,2 , and 3 alemtuzumab retreatment courses, respectively, over years 175 patients who achieved NEDA in year 2 and received no alemtuzumab retreatment after the initial 2 courses and no other DMT (figure e-1A). Most patients achieved NEDA in each year of the extension and $60.8 \%$ attained NEDA through years $2-5$, reflecting high proportions of relapse-free, 6-month CDW-free and new Gd-enhancing and T2 hyperintense lesion-free patients (figure e-1B); this cohort with sustained NEDA demonstrated slowing of median annual BVL (figure e-2).

Safety. AEs occurring in alemtuzumab-treated patients throughout the core and extension studies (up to the cutoff date; 1767.7 patient-years over 5-year followup) are summarized in tables 1 and 2 and table e- 2 . The EAIR for overall AEs was lower in the extension (years 3-5, 133.6) than in the core study (years $0-2$, 705.2). Serious $\mathrm{AE}$ incidence remained low over 5 years. Most AEs (96.9\%) in years 3-5 were mild to moderate in severity. No AEs led to study withdrawal in the extension. One death, reported previously, occurred during the extension (in year 3), due to sepsis that developed in the setting of pancytopenia and was judged by the investigator to be treatment-related. ${ }^{6}$ 


\begin{tabular}{|c|c|c|c|c|c|c|c|c|}
\hline & \multirow{2}{*}{\multicolumn{5}{|c|}{ Incidence, core and extension studies $(5 \mathrm{y}), \mathrm{n}(\%)^{a}$}} & \multicolumn{3}{|c|}{$\begin{array}{l}\text { EAIR per } 100 \text { patient-years } \\
\text { (no. of events) }^{b}\end{array}$} \\
\hline & & & & & & \multirow{2}{*}{$\begin{array}{l}\begin{array}{l}\text { Core } \\
\text { study } \\
(2 \text { y) }\end{array} \\
\text { Years 0-2 } \\
(\mathrm{n}=376)\end{array}$} & \multirow{2}{*}{$\begin{array}{l}\begin{array}{l}\text { Extension } \\
\text { study } \\
(3 \mathrm{y})\end{array} \\
\begin{array}{l}\text { Years 3-5 } \\
(\mathrm{n}=360)\end{array}\end{array}$} & \multirow{2}{*}{$\begin{array}{l}\begin{array}{l}\text { Core and } \\
\text { extension } \\
\text { studies } \\
(5 \mathrm{y})\end{array} \\
\text { Years } 0-5 \\
(\mathrm{n}=376)\end{array}$} \\
\hline & $\begin{array}{l}\text { Year } 1 \\
(n=376)\end{array}$ & $\begin{array}{l}\text { Year } 2 \\
(\mathrm{n}=376)\end{array}$ & $\begin{array}{l}\text { Year } 3 \\
\left(n=360^{c}\right)\end{array}$ & $\begin{array}{l}\text { Year } 4 \\
(n=344)\end{array}$ & $\begin{array}{l}\text { Year } 5 \\
(n=340)\end{array}$ & & & \\
\hline Any AE excluding IARs ${ }^{d}$ & $297(79.0)$ & $282(75.0)$ & $270(75.0)$ & 251 (73.0) & $231(67.9)$ & 174.8 & 129.2 & 146.6 \\
\hline AE leading to study drug discontinuation & $4(1.1)$ & $1(0.3)$ & 0 & 0 & 0 & $0.7(5)$ & 0 & $0.3(5)$ \\
\hline Any serious $A E$ & $45(12.0)$ & $29(7.7)$ & $36(10.0)$ & $29(8.4)$ & $17(5.0)$ & 10.1 & 7.0 & 7.8 \\
\hline Any serious AE excluding IARs & $36(9.6)$ & $27(7.2)$ & $36(10.0)$ & $29(8.4)$ & $17(5.0)$ & 8.3 & 7.0 & 6.9 \\
\hline Any thyroid disorder ${ }^{e, f}$ & 31 (8.2) & $48(12.8)$ & $60(16.7)$ & $22(6.4)$ & $10(2.9)$ & 11.5 & 15.1 & 13.2 \\
\hline Serious thyroid AEs & $2(0.5)$ & $2(0.5)$ & 12 (3.3) & $1(0.3)$ & $3(0.9)$ & $0.5(4)$ & 1.6 & 1.2 \\
\hline ITPe & $1(0.3)$ & $2(0.5)$ & 0 & $1(0.3)$ & 0 & $0.4(3)$ & $0.1(1)$ & $0.2(4)$ \\
\hline Nephropathy ${ }^{e}$ & 0 & 0 & $1(0.3)$ & 0 & 0 & 0 & $0.1(1)$ & 0.1 (1) \\
\hline Malignant disease & $1(0.3)$ & $1(0.3)$ & $1(0.3)$ & $1(0.3)$ & $2(0.6)$ & $0.3(2)$ & $0.4(4)$ & $0.3(6)$ \\
\hline
\end{tabular}

Abbreviations: $\mathrm{AE}$ = adverse event; EAIR = exposure-adjusted incidence rate; IAR = infusion-associated reaction; ITP = immune thrombocytopenia.

${ }^{a}$ Percentage is based on the number of patients having an $A E$ in the reported year divided by the total number of patients followed up in that year.

${ }^{b}$ (Number of patients with a specific event divided by the total exposure-time among patients at risk of an initial occurrence of the event) $\times 100$. Events occurring in $<1$ per 100 patient-years include the number of events in parentheses.

${ }^{c}$ In addition to the patients enrolled in the extension study, the safety analyses included a small number of core study patients ( $n=11$ ), who did not enter the extension but were evaluated for AEs temporarily after the initial 2-year period.

${ }^{d}$ All patients with any $A E$, excluding those patients whose only AEs were IARs. IARs were any AE that occurred during the infusion or within 24 hours after the end of the infusion.

${ }^{\mathrm{e}}$ Includes first event by year of occurrence.

${ }^{f}$ Defined as any thyroid AE or abnormal thyroid-stimulating hormone level, with simultaneously abnormal free triiodothyronine $\left(T_{3}\right)$ or free thyroxine $\left(T_{4}\right)$ on the same visit.

IAR incidences in patients receiving alemtuzumab retreatment in the extension were lower than in the core study (table 2). No serious IARs occurred during the extension (courses 3, 4, or 5). Similar to the core study, ${ }^{6}$ the most frequently reported IARs with alemtuzumab retreatment in the extension were headache, pyrexia, and rash. When IARs were removed from the count of any AEs overall, the EAIR remained lower in the extension (129.2) compared with that in the core study (174.8).

Overall incidences and EAIRs of infections over years 3-5 were lower than during the core study (table 1 and table e-2); 99.2\% were mild to moderate in severity. Infection incidence did not increase with successive alemtuzumab courses (table e-3). As in the core study, the most common infection events in the extension were nasopharyngitis, urinary tract infection, upper respiratory tract infection, and herpetic infections (predominantly mucocutaneous). The incidence of serious infections remained low; the most frequent was herpes zoster, with a total of 5 cases occurring over years $0-5$ (4 were during the extension).

The most common autoimmune AEs occurring during the extension were thyroid AEs, which peaked in year 3 and subsequently declined in years 4 and 5 (years 1-5 incidences: 6.4\%, 9.6\%, 15.3\%, $7.6 \%$, and $3.5 \%$; incidence over 5 years was $40.7 \%$ ). Of the thyroid AEs reported in years 3-5, 62.1\% were moderate and $27.1 \%$ were mild in severity. Similar incidences were observed over time for the broader category of thyroid disorders (table 1 and table e-2), which include abnormal thyroid function tests (thyroid-stimulating hormone, free triiodothyronine $\left[T_{3}\right]$, free thyroxine $\left[T_{4}\right]$ ) in addition to investigator-reported thyroid AEs; incidence over 5 years was $45.5 \%$. Few serious thyroid AEs were reported. As in the core study, the most frequently reported thyroid disorders in the extension were laboratory abnormalities, and clinical hyperthyroidism and hypothyroidism. Thirteen thyroidectomies were reported over years $0-5$; most patients undergoing 


\begin{tabular}{|c|c|c|c|c|c|c|c|}
\hline \multirow[b]{3}{*}{ IARs ${ }^{\text {b }}$ by course } & \multicolumn{7}{|c|}{ Incidence, $\mathrm{n}(\%)^{\mathrm{a}}$} \\
\hline & \multicolumn{2}{|l|}{ Core study } & \multicolumn{3}{|c|}{ Extension study } & \multirow{2}{*}{$\begin{array}{l}\begin{array}{l}\text { Patients } \\
\text { receiving } \\
\text { initial } 2 \\
\text { courses }\end{array} \\
\begin{array}{l}\text { Courses 1-2 } \\
(n=376)\end{array}\end{array}$} & \multirow{2}{*}{$\begin{array}{l}\begin{array}{l}\text { Patients } \\
\text { receiving } \\
\text { retreatment }\end{array} \\
\begin{array}{l}\text { Courses 3-5 } \\
\text { (n= 110) }\end{array}\end{array}$} \\
\hline & $\begin{array}{l}\text { Course } 1 \\
(n=376)\end{array}$ & $\begin{array}{l}\text { Course } 2 \\
(n=370)\end{array}$ & $\begin{array}{l}\text { Course } 3 \\
(n=110)\end{array}$ & $\begin{array}{l}\text { Course } 4 \\
(n=33)\end{array}$ & $\begin{array}{l}\text { Course } 5 \\
(n=5)\end{array}$ & & \\
\hline Any IAR & 323 (85.9) & $243(65.7)$ & 72 (65.5) & $18(54.5)$ & $2(40.0)$ & 338 (89.9) & $73(66.4)$ \\
\hline \multicolumn{8}{|c|}{$\begin{array}{l}\text { IAR events affecting }>10 \% \text { of } \\
\text { patients over courses } 1-5\end{array}$} \\
\hline Rash $^{c}$ & $154(41.0)$ & 65 (17.6) & 13 (11.8) & 5 (15.2) & 1 (20.0) & 165 (43.9) & 15 (13.6) \\
\hline Headache & $133(35.4)$ & $103(27.8)$ & 31 (28.2) & 6 (18.2) & 0 & $160(42.6)$ & 33 (30.0) \\
\hline Pyrexia & 81 (21.5) & 63 (17.0) & 19 (17.3) & $3(9.1)$ & $1(20.0)$ & 125 (33.2) & $22(20.0)$ \\
\hline Nausea & 40 (10.6) & 21 (5.7) & $9(8.2)$ & 4 (12.1) & 0 & $52(13.8)$ & 13 (11.8) \\
\hline Flushing & $30(8.0)$ & $20(5.4)$ & $4(3.6)$ & $3(9.1)$ & 0 & 43 (11.4) & $6(5.5)$ \\
\hline Urticaria & 38 (10.1) & 11 (3.0) & $3(2.7)$ & 0 & 0 & 43 (11.4) & $3(2.7)$ \\
\hline Pruritus $^{d}$ & $30(8.0)$ & $10(2.7)$ & $1(0.9)$ & 5 (15.2) & 0 & 39 (10.4) & $6(5.5)$ \\
\hline Chills & $28(7.4)$ & 14 (3.8) & $5(4.5)$ & 0 & 0 & 38 (10.1) & 5 (4.5) \\
\hline Insomnia & $23(6.1)$ & $18(4.9)$ & $7(6.4)$ & 1 (3.0) & 0 & 37 (9.8) & $8(7.3)$ \\
\hline Serious IARs ${ }^{e}$ & $10(2.7)$ & $2(0.5)$ & 0 & 0 & 0 & 12 (3.2) & 0 \\
\hline
\end{tabular}

Abbreviation: IAR = infusion-associated reaction.

a Percentage is based on the number of patients having an IAR in the reported course divided by the total number of patients followed up for that course.

${ }^{\mathrm{b}}$ IARs were any adverse event that occurred during the infusion or within 24 hours after the end of the infusion.

${ }^{\mathrm{c}}$ Rash includes the preferred terms rash and rash generalized.

${ }^{\mathrm{d}}$ Pruritus includes the preferred terms pruritus and pruritus generalized.

e The following serious IARs occurred in 2 patients each: atrial fibrillation (course 1), incorrect dose administered (course 1), and hypotension (course 1). The following serious IARs occurred in 1 patient each: anaphylactic shock (course 1), angioedema (course 1), bradycardia (course 1), brain stem syndrome (course 2), chest discomfort (course 1), headache (course 2), migraine (course 1), myalgia (course 2), nausea (course 2), pleurisy (course 1), pyrexia (course 2), sinus bradycardia (course 1), sinus tachycardia (course 1), tachycardia (course 2), throat tightness (course 1), and urticaria (course 1). No serious IARs occurred in courses 3,4 , or 5 .

thyroidectomies were subsequently maintained on thyroxine.

One new case of ITP was reported during the extension (year 4). The patient had a postalemtuzumab history of autoimmune hemolytic anemia that had resolved with treatment 2 years before ITP onset. At last follow-up, the patient was receiving oral prednisone for ITP, which was considered resolved several months after the initial event.

There was a single case of nephropathy reported in year 3 (4 months after the third alemtuzumab course). The patient presented with hematuria and proteinuria. Serum creatinine levels remained normal, but there was weak seropositivity for antiglomerular basement membrane autoantibodies. A renal biopsy revealed focal global glomerulosclerosis and changes indicative of membranous nephropathy, but no evidence of antiglomerular basement membrane disease. By 39 months after the initial event, following treatment with plasmapheresis, glucocorticosteroids, and cyclophosphamide, serum creatinine levels remained normal, proteinuria was absent, and the patient did not develop kidney failure.
Over 5 years, a total of 6 malignancies were reported in alemtuzumab-treated patients (EAIR of 0.3 per 100 patient-years). Two malignancies occurred in the core study (both papillary thyroid carcinomas), and 4 malignancies were reported in years 3-5 ( $\mathrm{n}=1$ each for breast cancer, keratoacanthoma, non-small-cell lung cancer, and micropapillary thyroid carcinoma).

DISCUSSION Damage to neurons and axons starts in the earliest stages of MS and is clinically relevant, as it may foreshadow evolution of neurologic disability. ${ }^{12,13}$ CNS tissue destruction can be quantified by MRI as cerebral atrophy, which is accelerated in patients with MS compared with healthy individuals. ${ }^{14}$ Thus, to prevent accumulation of permanent neurologic damage, early intervention in MS is important and warranted. ${ }^{15}$ However, experts have not reached consensus regarding what constitutes appropriate early-stage treatment for patients with adverse prognostic factors (e.g., an early disease course that includes frequent relapses, MRI lesion volume change, or brain atrophy). ${ }^{16-18}$ Some physicians may initially 
prescribe a low- to moderate-efficacy therapy and may switch to high-efficacy therapy upon evidence of an inadequate response (e.g., disease activity while on therapy), whereas others favor an individualized approach involving higher-efficacy agents from the outset. ${ }^{19}$ CARE-MS I compared these approaches in patients with active RRMS and found greater improvements in relapse and MRI outcomes, as well as higher attainment of NEDA, in patients who received alemtuzumab compared with SC IFN- $\beta-1 a .^{6}$

We show that these findings were extended in the CARE-MS I alemtuzumab treatment arm, with durable improvements in key efficacy outcomes over 5 years, including low ARR and most patients having stable/improved EDSS scores and freedom from 6-month CDW. Additionally, more than one-third achieved 6-month CDI. This endpoint captures durable and clinically meaningful EDSS score changes in individual patients with preexisting neurologic impairments; improving disability in those patients may lead to better long-term prognosis. ${ }^{20}$ Our study reports durable improvement in disability by using this stringent outcome measure over several years in a large MS patient cohort. Additionally, during each of years 3, 4, and 5, a consistent proportion of about $60 \%$ of patients achieved NEDA; when the rigorous goal of sustained NEDA was assessed cumulatively over years 3-5, $40 \%$ of patients satisfied this endpoint. These effects were observed in the absence of continuous treatment and despite no retreatment in the majority of patients. Similar durable efficacy improvements were also shown for patients with active RRMS who had an inadequate response to prior therapy. ${ }^{21}$

Previous studies have shown the predictive value of brain atrophy on disability outcomes in the early years after MS diagnosis. ${ }^{18}$ Treatment effects on brain atrophy and lesion activity correlate with treatment effects on disability and cognitive dysfunction for some therapies. ${ }^{14,18,22-24}$ No current therapies are known to reverse CNS damage. Alemtuzumab slowed the annual rate of BVL over years 3-5. Moreover, alemtuzumab-treated patients showed less cumulative atrophy after 5 years (reported in this study) compared with that observed in patients who had received SC IFN- $\beta$-1a in the core study and then switched to alemtuzumab in the extension (median BPF changes of $-1.352 \%$ vs $-1.646 \%$, respectively; $p=0.0086),{ }^{25}$ illustrating the long-term benefits of early treatment with alemtuzumab.

Durable efficacy with alemtuzumab over the 3-year extension follow-up was accompanied by a safety profile consistent with that observed in the core study. Overall AEs, including IARs and infections, decreased over time relative to the core study, with a low but persistent risk of herpes zoster reactivation.
Autoimmune thyroid AEs peaked at year 3 and declined thereafter. The rate of malignancies did not increase from the core study through the extension. Two cases of papillary thyroid carcinomas were seen in the core study; only 1 new micropapillary thyroid carcinoma event was reported over the next 3 years. The apparent rate of thyroid malignancies observed with alemtuzumab in the MS clinical trial program may have been inflated by ascertainment bias owing to a more frequent occurrence of nonmalignant thyroid disorders and their diagnostic workup $^{26}$ with alemtuzumab than with SC IFN$\beta-1 \mathrm{a}$. These observations relating to safety with alemtuzumab are in contrast to $\mathrm{AE}$ rates that have been observed with long-term use of chronically dosed DMTs, in which the known risks associated with a particular agent may increase or remain constant with continued exposure to drug. ${ }^{27-29}$ With alemtuzumab, because of its unique dosing schedule and lack of continuous treatment, most risks decrease over time. Procedures for regular monitoring and management help to maximize the risk-benefit profile.

As is often cited as a limitation of extension studies, the active comparator design of the pivotal CARE-MS trials ${ }^{6,7}$ was not continued in the extension period, thus precluding long-term direct comparison with another treatment. Nonetheless, these 5-year data from patients who were treatment-naive and had a mean disease duration of 2 years upon entry into CARE-MS I demonstrate durable, long-term therapeutic effects on clinical disease activity measures, as well as on more objective measures such as MRI lesion activity and brain atrophy. The robustness of our results is supported by the high patient enrollment rate coupled with the unusually high retention rate ( $>95 \%$ through year 5$)$. Notably, the latter suggests that the favorable outcomes in our study cannot reflect selective dropout of poor responders. The continued use of blinded raters also helped ensure unbiased efficacy analyses.

The sustained responses to alemtuzumab observed over 5 years in our study highlight the value of a durable, high-efficacy therapy in the absence of continuous treatment in patients who may be at high risk of MS-related disability worsening and BVL. Risks associated with the therapy are anticipated in advance of treatment, and monitoring procedures for minimizing adverse effects are implemented to maintain a positive risk-benefit profile.

\section{AUTHOR CONTRIBUTIONS}

E.H., J.A.C., H.-P.H., E.J.F., G.G., S.S., K.W.S., A.T., D.A.S.C., and A.J.C. contributed to study design, data collection, writing and critical review of the manuscript, and approved the final submission draft. D.L.A. contributed to data collection, writing and critical review of the manuscript, and approved the final submission draft. D.H.M. and M.A.P. contributed to study design, writing and critical review of the 
manuscript, and approved the final submission draft. C.E.R and D.J. contributed to writing and critical review of the manuscript, and approved the final submission draft. K.T. led statistical support and also contributed to the writing and critical review of the manuscript, and approved the final submission draft. R.J.H. and P.X. provided editorial and medical writing support (assistance in drafting the manuscript, technical editing, copyediting, and responding to reviewers' comments), and approved the final submission draft.

\section{ACKNOWLEDGMENT}

Critical review of the manuscript was provided by Darren P. Baker, PhD, Madalina C. Chirieac, MD, MPH, Vladimir Evilevitch, MD, $\mathrm{PhD}$, Maria Melanson, MD, PhD, and Sarah Strattman, MS, of Sanofi. Kunio Nakamura, PhD, oversaw BPF analyses and was an employee of the Department of Biomedical Engineering, Cleveland Clinic, Cleveland, $\mathrm{OH}$, at the time the work was conducted. Additional statistical support was provided by Linda Kasten, BS, MA, who received compensation (Sanofi) as an employee of PROMETRIKA, LLC, when the statistical analyses were performed; currently an employee of Biostatistical Consulting, Inc. Catherine Pennella, BS, of Sanofi assisted in safety analyses.

\section{STUDY FUNDING}

Supported by Sanofi and Bayer HealthCare Pharmaceuticals.

\section{DISCLOSURE}

E. Havrdova reports receiving honoraria and grant support from Actelion, Biogen, Merck Serono, Novartis, Receptos, Roche, Sanofi Genzyme, and Teva, and is supported by Ministry of Education of Czech Republic, project PRVOUK-P26/LF1/4. D.L. Arnold reports receiving compensation for serving as a speaker, consultant, and advisory board participant, and receiving research support from Acorda, Bayer, Biogen, Eli Lilly, EMD Serono, Genentech, GlaxoSmithKline, MedImmune, Merck Serono, NeuroRx Research, Novartis, Opexa Therapeutics, Receptos, Roche, Sanofi Genzyme, Teva, the Canadian Institutes of Health Research, and the Multiple Sclerosis Society of Canada. J.A. Cohen reports personal compensation for consulting for Genentech, Merck, Novartis, and Receptos and as a coeditor of Multiple Sclerosis Journal-Experimental, Translational and Clinical. H.-P. Hartung reports receiving honoraria for consulting and speaking at symposia from Bayer HealthCare, Biogen, CSL Behring, Grifols, Merck Serono, Novartis, Roche, and Sanofi Genzyme. E.J. Fox reports receiving consulting fees, honoraria, travel, and research support from Acorda, Bayer HealthCare, Biogen, EMD Serono, Genentech, Novartis, Opexa Therapeutics, Sanofi Genzyme, and Teva. G. Giovannoni reports having served as a consultant or received research support from AbbVie, Bayer HealthCare, Biogen, Canbex Therapeutics, Five Prime Therapeutics, GlaxoSmithKline, GW Pharma, Merck Serono, Novartis, Oxford PharmaGenesis, Protein Discovery Laboratories, Roche, Sanofi Genzyme, Synthon, Teva, and UCB. S. Schippling reports receiving research grants from Novartis and Sanofi Genzyme; and consulting and speaking fees from Biogen, Merck Serono, Novartis, Sanofi Genzyme, and Teva. K.W. Selmaj reports receiving consulting fees from Biogen, Merck, Novartis, Roche, Sanofi Genzyme, and Synthon. A. Traboulsee reports receiving consulting fees from Biogen, Novartis, Roche, Sanofi Genzyme, Serono, and Teva Innovation; and has been a principal investigator on clinical trials funded by Roche and Sanofi Genzyme. D.A.S. Compston reports receiving consulting fees and grant support from Genzyme and lecture fees from Bayer Schering Pharma on behalf of the University of Cambridge; and personal remuneration for lecture fees from Genzyme from July 2014. D.H. Margolin, K. Thangavelu, C.E. Rodriguez, and D. Jody report receiving personal compensation as an employee of Sanofi. R.J. Hogan and P. Xenopoulos report receiving personal compensation as an employee of Evidence Scientific Solutions. M.A. Panzara received personal compensation as an employee of Sanofi during study conduct and analysis and during preparation of the manuscript. A.J. Coles reports receiving consulting fees, lecture fees, and institutional grant support from Sanofi Genzyme. Go to Neurology.org for full disclosures.

Received August 9, 2016. Accepted in final form February 23, 2017.

\section{REFERENCES}

1. Weber MS, Hemmer B. Cooperation of B cells and T cells in the pathogenesis of multiple sclerosis. Results Probl Cell Differ 2010;51:115-126.

2. Hu Y, Turner MJ, Shields J, et al. Investigation of the mechanism of action of alemtuzumab in a human CD52 transgenic mouse model. Immunology 2009; 128:260-270.

3. Rao SP, Sancho J, Campos-Rivera J, et al. Human peripheral blood mononuclear cells exhibit heterogeneous CD52 expression levels and show differential sensitivity to alemtuzumab mediated cytolysis. PLoS One 2012;7:e39416.

4. Cox AL, Thompson SA, Jones JL, et al. Lymphocyte homeostasis following therapeutic lymphocyte depletion in multiple sclerosis. Eur J Immunol 2005;35:3332-3342.

5. CAMMS223 Trial Investigators, Coles AJ, Compston DA, et al. Alemtuzumab vs. interferon beta-1a in early multiple sclerosis. N Engl J Med 2008;359:1786-1801.

6. Cohen JA, Coles AJ, Arnold DL, et al. Alemtuzumab versus interferon beta $1 \mathrm{a}$ as first-line treatment for patients with relapsing-remitting multiple sclerosis: a randomised controlled phase 3 trial. Lancet 2012;380:1819-1828.

7. Coles AJ, Twyman CL, Arnold DL, et al. Alemtuzumab for patients with relapsing multiple sclerosis after diseasemodifying therapy: a randomised controlled phase 3 trial. Lancet 2012;380:1829-1839.

8. LEMTRADA [Summary of Product Characteristics] [online]. Oxford, United Kingdom: Genzyme Therapeutics, Ltd. Available at: ema.europa.eu/docs/en_GB/document_ library/EPAR_-_Product_Information/human/003718/ WC500150521.pdf. Accessed May 30, 2014.

9. LEMTRADA (Alemtuzumab), for Intravenous Injection [Prescribing Information]. Cambridge, MA: Genzyme Corporation; 2014.

10. Lublin FD, Reingold SC, Cohen JA, et al. Defining the clinical course of multiple sclerosis: the 2013 revisions. Neurology 2014;83:278-286.

11. Liu GF, Wang J, Liu K, Snavely DB. Confidence intervals for an exposure adjusted incidence rate difference with applications to clinical trials. Stat Med 2006;25: 1275-1286.

12. Comi G. Shifting the paradigm toward earlier treatment of multiple sclerosis with interferon beta. Clin Ther 2009;31: 1142-1157.

13. Rush CA, MacLean HJ, Freedman MS. Aggressive multiple sclerosis: proposed definition and treatment algorithm. Nat Rev Neurol 2015;11:379-389.

14. Zivadinov R, Reder AT, Filippi M, et al. Mechanisms of action of disease-modifying agents and brain volume changes in multiple sclerosis. Neurology 2008;71: 136-144.

15. Multiple Sclerosis Therapy Consensus Group (MSTCG), Wiendl H, Toyka KV, et al. Basic and escalating immunomodulatory treatments in multiple sclerosis: current therapeutic recommendations. J Neurol 2008;255:1449-1463.

16. Scalfari A, Neuhaus A, Degenhardt A, et al. The natural history of multiple sclerosis: a geographically based study 10: relapses and long-term disability. Brain 2010;133: 1914-1929.

17. Fisniku LK, Brex PA, Altmann DR, et al. Disability and T2 MRI lesions: a 20-year follow-up of patients with relapse onset of multiple sclerosis. Brain 2008;131: 808-817. 
18. Popescu V, Agosta F, Hulst HE, et al. Brain atrophy and lesion load predict long term disability in multiple sclerosis. J Neurol Neurosurg Psychiatry 2013;84:1082-1091.

19. Rieckmann P. Concepts of induction and escalation therapy in multiple sclerosis. J Neurol Sci 2009;277(suppl 1): S42-S45.

20. Coles AJ, Fox E, Vladic A, et al. Alemtuzumab versus interferon beta-1a in early relapsing-remitting multiple sclerosis: post-hoc and subset analyses of clinical efficacy outcomes. Lancet Neurol 2011;10:338-348.

21. Fox EJ, Arnold DL, Cohen JA, et al. Durable efficacy of alemtuzumab on clinical outcomes over 5 years in CAREMS II with most patients free from treatment for 4 years. Mult Scler 2015;21(suppl 11):P1102.

22. Fisher E, Rudick RA, Cutter G, et al. Relationship between brain atrophy and disability: an 8-year followup study of multiple sclerosis patients. Mult Scler 2000; 6:373-377.

23. Jacobsen C, Hagemeier J, Myhr KM, et al. Brain atrophy and disability progression in multiple sclerosis patients: a 10-year follow-up study. J Neurol Neurosurg Psychiatry 2014;85:1109-1115.
24. Sormani MP, Arnold DL, De Stefano N. Treatment effect on brain atrophy correlates with treatment effect on disability in multiple sclerosis. Ann Neurol 2014;75:43-49.

25. Barkhof F, Cohen JA, Coles A, et al. RRMS patients switching from SC IFNB-1a to alemtuzumab in the CARE-MS I and II extension study have a reduced rate of brain volume loss (P6.183). Neurology 2016;86 (suppl):16.

26. Schneider DF, Chen H. New developments in the diagnosis and treatment of thyroid cancer. CA Cancer J Clin 2013;63:374-394.

27. Butzkueven H, Kappos L, Pellegrini F, et al. Efficacy and safety of natalizumab in multiple sclerosis: interim observational programme results. J Neurol Neurosurg Psychiatry 2014;85:1190-1197.

28. O'Connor P, Goodman A, Kappos L, et al. Long-term safety and effectiveness of natalizumab redosing and treatment in the STRATA MS Study. Neurology 2014; 83:78-86.

29. Bloomgren G, Richman S, Hotermans C, et al. Risk of natalizumab-associated progressive multifocal leukoencephalopathy. N Engl J Med 2012;366:1870-1880.

$\begin{array}{|ll|} & \text { Practice Current: An interactive exchange } \\ & \text { on controversial topics } \\ & \text { Share your own best practices. } \\ \text { Read commentary with expert opinion. } \\ \text { Explore results on an interactive world map. } \\ \text { http://bit.ly/CPpractice3 }\end{array}$

\section{Pit Neurology.org Offers Important Information to Patients and Their Families}

The Neurology ${ }^{\circledR}$ Patient Page provides:

- A critical review of ground-breaking discoveries in neurologic research that are written especially for patients and their families

- Up-to-date patient information about many neurologic diseases

- Links to additional information resources for neurologic patients

All Neurology Patient Page articles can be easily downloaded and printed, and may be reproduced to distribute for educational purposes. Click on the 'Patients' link on the home page (Neurology.org) for a complete index of Patient Pages. 


\section{Neurology}

\section{Alemtuzumab CARE-MS I 5-year follow-up: Durable efficacy in the absence of continuous MS therapy}

Eva Havrdova, Douglas L. Arnold, Jeffrey A. Cohen, et al.

Neurology 2017;89;1107-1116 Published Online before print August 23, 2017

DOI 10.1212/WNL.0000000000004313

This information is current as of August 23, 2017

Neurology ${ }^{\circledR}$ is the official journal of the American Academy of Neurology. Published continuously since 1951, it is now a weekly with 48 issues per year. Copyright Copyright (C) 2017 The Author(s). Published by Wolters Kluwer Health, Inc. on behalf of the American Academy of Neurology. All rights reserved. Print ISSN: 0028-3878. Online ISSN: 1526-632X.

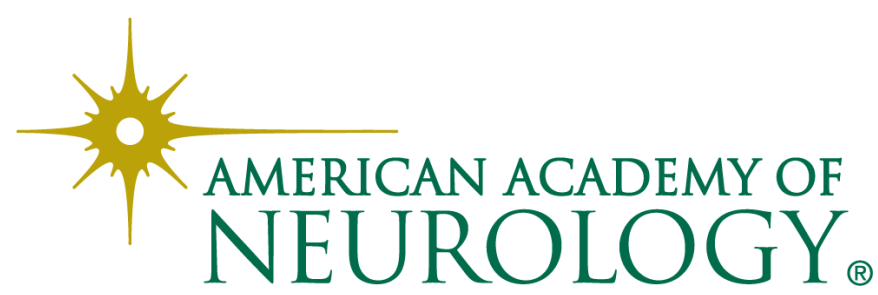




\section{Updated Information \& Services}

\section{Supplementary Material}

\section{References}

\section{Citations}

\section{Subspecialty Collections}

\section{Errata}

Permissions \& Licensing

\section{Reprints}

including high resolution figures, can be found at: http://n.neurology.org/content/89/11/1107.full

Supplementary material can be found at: http://n.neurology.org/content/suppl/2017/08/23/WNL.0000000000004 313.DC1

http://n.neurology.org/content/suppl/2017/08/23/WNL.0000000000004 313.DC2

http://n.neurology.org/content/suppl/2017/08/23/WNL.0000000000004 313.DC3

This article cites 27 articles, 5 of which you can access for free at: http://n.neurology.org/content/89/11/1107.full\#ref-list-1

This article has been cited by 10 HighWire-hosted articles: http://n.neurology.org/content/89/11/1107.full\#\#otherarticles

This article, along with others on similar topics, appears in the following collection(s):

Autoimmune diseases

http://n.neurology.org/cgi/collection/autoimmune_diseases

\section{Class III}

http://n.neurology.org/cgi/collection/class_iii

Clinical trials Randomized controlled (CONSORT agreement) http://n.neurology.org/cgi/collection/clinical_trials_randomized_control led_consort_agreement

Multiple sclerosis

http://n.neurology.org/cgi/collection/multiple_sclerosis

An erratum has been published regarding this article. Please see next page or:

/content/90/16/755.full.pdf

Information about reproducing this article in parts (figures,tables) or in its entirety can be found online at:

http://www.neurology.org/about/about_the_journal\#permissions

Information about ordering reprints can be found online:

http://n.neurology.org/subscribers/advertise

Neurology ${ }^{\circledR}$ is the official journal of the American Academy of Neurology. Published continuously since 1951, it is now a weekly with 48 issues per year. Copyright Copyright ( 2017 The Author(s). Published by Wolters Kluwer Health, Inc. on behalf of the American Academy of Neurology. All rights reserved. Print ISSN: 0028-3878. Online ISSN: 1526-632X.

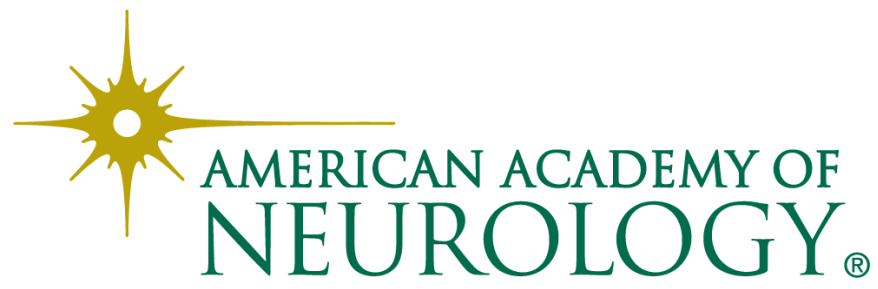




\section{Disputes \& Debates: Editors' Choice}

Robert C. Griggs, MD, FAAN, Section Editor; Steven Galetta, MD, FAAN, Co-Editor

\section{Editors' note: Teaching Video Neurolmages: Olivary enlargement and pharyngeal nystagmus}

In "Teaching Video NeuroImages: Olivary enlargement and pharyngeal nystagmus," authors Finlay and Yacovino described a 77-year-old woman with a pontine cavernoma and rhythmic contractions of the soft palate and upper larynx on videofluoroscopy. The accompanying MRI showed right inferior olivary nucleus hypertrophy. Dr. Bhattacharjee comments that the simultaneous palate-pharyngeal tremor may be due to their common innervation by the vagus nerve. He also asks about the interval between the cavernoma expansion, the radiologic signal changes, and the patient's symptoms. Authors Finlay and Yacovino clarify that the olivary hypertrophy was present on the patient's initial MRI and that the palatal tremor was diagnosed 36 months after that study. They also note that synchronic contraction additionally was seen in the bilateral eyelids in their patient, which does not support Dr. Bhattacharjee's theory of common vagus nerve innervation. Dr. Mendez-Guerrero suggests that the term pharyngeal nystagmus, coined a century ago, may be misleading as a central nystagmus now infers a vestibular nuclei or vestibular pathway impairment, which is not present in this disorder. He proposes using the term pharyngeal/laryngeal myorhythmia, denoting a slow $(2-3 \mathrm{~Hz})$ rhythmic movement disorder of the cranial musculature. The authors expand on the terminology mentioned by Dr. Mendez-Guerrero and on their use of Spencer's original nomenclature.

Megan Alcauskas, MD, and Steven Galetta, MD

Neurology ${ }^{\circledR}$ 2018;90:753. doi:10.1212/WNL.0000000000005318

\section{Reader response: Teaching Video NeuroImages: Olivary enlargement and pharyngeal nystagmus}

Shakya Bhattacharjee (Truro, United Kingdom)

Neurology ${ }^{\circledR}$ 2018;90:753-754. doi:10.1212/WNL.0000000000005316

The interesting Teaching Video NeuroImage by Drs. Finlay and Yacovino ${ }^{1}$ demonstrated simultaneous soft palate and pharyngeal tremor and hypertrophic olivary degeneration (HOD). The palatal tremor is secondary to levator veli palatini contraction. The levator veli palatini is mainly supplied by the vagus nerve via the pharyngeal plexus. Most of the pharyngeal muscles are supplied by the vagus nerve, so simultaneous palate-pharyngeal tremor can be explained by the common nerve supply.

The authors demonstrated unilateral olivary degeneration, ${ }^{1}$ which is less often found to be idiopathic than bilateral HOD. ${ }^{2}$ However, olivary hypertrophy usually appears 4-6 months after the initial insult and the soft palatal tremor appears after 10-11 months of the initial insult. ${ }^{3}$ In the presented patient, the insult is most likely either the expansion of the pontine cavernoma or the cavernous bleed. It would be interesting to know the interval among the cavernoma expansion/ bleed and the appearance of the radiologic signal changes in the inferior olive and the palatopharyngeal tremor. 
1. Finlay JB, Yacovino DA. Teaching Video NeuroImages: olivary enlargement and pharyngeal nystagmus. Neurology $2017 ; 89:$ e168.

2. Konno T, Broderick DF, Tacik P, Caviness JN, Wszolek ZK. Hypertrophic olivary degeneration: a clinico-radiologic study. Parkinsonism Relat Disord 2016;28:36-40.

3. Choh NA, Choh SA, Jehangir M. Hypertrophic olivary degeneration: the forgotten triangle of Guillain and Mollaret. Neurol India 2009; 57:507-509.

\title{
Reader response: Teaching Video NeuroImages: Olivary enlargement and pharyngeal nystagmus
}

\begin{abstract}
Antonio Mendez-Guerrero, Roberto Lopez-Blanco, and David Uriarte-Perez de Urabayen (Madrid, Spain)
\end{abstract} Neurology ${ }^{\circledR}$ 2018;90:754. doi:10.1212/WNL.0000000000005319

We noted with interest the Teaching Video NeuroImage by Drs. Finlay and Yacovino. ${ }^{1}$ The authors examined the phenomenology of a rare slow movement disorder of pharynx and larynx due to a brainstem cavernoma using videofluoroscopy. The term pharyngeal nystagmus, beyond the initial description more than a century ago, ${ }^{2}$ may mislead readers. Central nystagmus implies a vestibular nuclei or vestibular pathway impairment ${ }^{3}$ that are not related to this movement disorder. Hence, pharyngeal nystagmus was known as palatine myoclonus/tremor, in which the dentate-rubro-olivary tract is commonly involved. ${ }^{4}$ This term is also problematic due to its phenomenologic differences with true myoclonus. Currently, this movement disorder is better considered part of the spectrum of myorhythmias: slow $(2-3 \mathrm{~Hz})$ rhythmic movement disorders of cranial musculature or limbs. ${ }^{5}$ We suggest that the term pharyngeal nystagmus be avoided and replaced by pharyngeal/laryngeal myorhythmia.

\footnotetext{
1. Finlay JB, Yacovino DA. Teaching Video NeuroImages: olivary enlargement and pharyngeal nystagmus. Neurology 2017;89:e168. Spencer HR. Pharyngeal and laryngeal "nystagmus." Lancet 1886;2:702-704.

Kheradmand A, Colpak AI, Zee DS. Eye movements in vestibular disorders. Handb Clin Neurol 2016;137:103-117.

Guillain G, Mollaret P. Deux cas de myoclonies synchrones et rythmees velo-pharyngo-laryngo-oculo-diaphragmatigues: le probleme anatomique et physio-pathologique de ce syndrom. Rev Neurol 1931;2:545-566.

5. Baizabal-Carvallo JF, Cardoso F, Jankovic J. Myorhythmia: phenomenology, etiology, and treatment. Mov Disord 2015;30:171-179.

Copyright @ 2018 American Academy of Neurology
}

\section{Author response: Teaching Video NeuroImages: Olivary enlargement and pharyngeal nystagmus}

Darío A. Yacovino (Ciudad de Buenos Aires, Argentina) and John B. Finlay (Princeton)

Neurology ${ }^{\circledR}$ 2018;90:754-755. doi:10.1212/WNL.0000000000005344

We appreciate the comments made by Dr. Bhattacharjee regarding our Teaching Video NeuroImage. ${ }^{1}$ The cavernoma was an incidental feature on the brain CT conducted after the patient had a fall, and mild hypertrophy olivary degeneration (HOD) was already visible on the subsequent MRI. However, the palatal tremor (PT) was not diagnosed until 36 months after the first studies. Here, PT and HOD are the manifestation of denervation supersensitivity, secondary to lesions involving the unilateral supraolivary central tegmental tract (CTT). According to the anatomical and radiologic changes in HOD, the MRI would likely not detect pseudohypertrophy early on or after a substantial time following Mollaret triangle injury. ${ }^{2}$

With a cavernoma, a direct expansion, bleeding/gliosis, or direct neurotoxicity induced by the hemosiderosis effect on the CTT are possible. ${ }^{3}$ The last would explain the progressive and silent deafferentation of the ipsilateral olivary nucleus.

Dr. Bhattacharjee's observation that the concert of pharyngeal muscle contraction in our case was mainly innervated by the vagus nerve is interesting; however, the same synchronic contraction was 
described in the eyelids, facial muscles, and diaphragm, which are innervated by other nerves. ${ }^{4}$ After review of the video-oculographic study, we identified similar bilateral synchronic eyelid contraction.

We also appreciate the clarifying comments made by Mendez-Guerrero et al. regarding our article, ${ }^{1}$ and reciprocally comment on some of the terms used.

Similar to congenital nystagmus, the involuntary rhythmic ocular movement in oculopalatal tremor is classified as pendular nystagmus and satisfies the characteristics to be defined as central nystagmus. ${ }^{5}$ However, the mechanism here is not primarily a central vestibular impairment; thus, it is not entirely accurate to attribute all cases of central nystagmus to a vestibular defect.

We agree there is a discrepancy in the terminology of palatal movement: tremor, myoclonus, and myorhythmia are used interchangeably in the literature. ${ }^{6}$ Although it resembles a tremor, the movement is often repetitive rather than oscillatory and only involves pharyngeal constrictor muscles, so it is commonly considered a myoclonus, as in our case. ${ }^{1}$

We highlighted the valuable clinical parallels between the movement of the eyes and the pharynx, which Spencer ${ }^{7}$ summarized under the term pharyngeal nystagmus, a typical observation of the clinicians of the time. While the formal terminology has not yet been established, we apologize for the slight departure from strict etymologic accuracy and thank MendezGuerrero et al. for prompting us to expand on the content in the case.

1. Finlay JB, Yacovino DA. Teaching Video NeuroImages: olivary enlargement and pharyngeal nystagmus. Neurology 2017;89:e168.

2. Goyal M, Versnick E, Tuite P, et al. Hypertrophic olivary degeneration: metaanalysis of the temporal evolution of MR findings. AJNR Am J Neuroradiol 2000;21:1073-1077.

3. Kumar N, Eggers SD, Milone M, Keegan BM. Acquired progressive ataxia and palatal tremor: importance of MRI evidence of hemosiderin deposition and vascular malformations. Parkinsonism Relat Disord 2011;17:565-568.

4. Deuschl G, Mischke G, Schenck E, Schulte-Monting J, Lucking CH. Symptomatic and essential rhythmic palatal myoclonus. Brain 1990; 113:1645-1672.

5. Leigh JR, Zee DS. The Neurology of Eye Movements, 5th ed. New York: Oxford University Press; 2015.

6. Tilikete C, Desestret V. Hypertrophic olivary degeneration and palatal or oculopalatal tremor. Front Neurol 2017;8:302.

7. Spencer HR. Pharyngeal and laryngeal "nystagmus". Lancet 1886;128:702. Letter.

Copyright (c) 2018 American Academy of Neurology

\section{CORRECTION}

\section{Alemtuzumab CARE-MS I 5-year follow-up: Durable efficacy in the absence of continuous MS therapy}

Neurology ${ }^{\circledR}$ 2018;90:755. doi:10.1212/WNL.0000000000004908

In the article "Alemtuzumab CARE-MS I 5-year follow-up: Durable efficacy in the absence of continuous MS therapy" by E. Havrdova et al.," the title should read "Alemtuzumab CARE-MS I 5-year follow-up: Efficacy in the absence of continuous MS therapy." The word "durable" was removed by the Editors during the review process and it was later reinserted in error.

\section{Reference}

1. Havrdova E, Arnold DL, Cohen JA, et al. Alemtuzumab CARE-MS I 5-year follow-up: durable efficacy in the absence of continuous MS therapy. Neurology 2017;89:1107-1116. 